\title{
Validated Reversed-Phase Liquid Chromatographic Method for Simultaneous Determination of Dextromethorphan and Chlorpheniramine in Non-biological and Biological Matrices Using PDA Detector
}

Najam ud Din, Shafi $H^{*}$, Imran M, Sarwar M, Tahir MA and Khursheed S

Punjab forensic science agency, Forensic Toxicology, Thokar niaz baig, Multan Road, Lahore, Punjab 53700, Pakistan

\begin{abstract}
A simple, precise and sensitive reversed-phase HPLC method using Photo-diode array detector for simultaneous determination of dextromethorphan (DXM) and chlorpheniramine (CLP) in various matrices had been developed and validated. The separation was achieved within 8 minutes on a C-18 column $(15 \mathrm{~cm} \times 4.6 \mathrm{~mm} \times 5 \mu \mathrm{m})$ using methanol/ $\mathrm{pH} 3.0$ potassium dihydrogen phosphate buffer $(60: 40, \mathrm{v} / \mathrm{v})$ mobile phase in an isocratic elution mode with flow rate $0.8 \mathrm{~mL} / \mathrm{min}$ and UV-detection at $230 \mathrm{~nm}$. External standard was employed for quantification. The current method demonstrated good linearity ranged $1-200 \mu \mathrm{g} / \mathrm{mL}$ for CLP (retention time $3.83 \pm 0.10 \mathrm{~min}$ ) with $\mathrm{r} 2$ of 0.9994 and $2-1000 \mu \mathrm{g} / \mathrm{mL}$ for DXM (retention time $5.02 \pm 0.10 \mathrm{~min}$ ) with R2 of 0.9993 . The limits of detection and quantification were $0.25 \mu \mathrm{g} / \mathrm{mL}$ and $1.0 \mu \mathrm{g} / \mathrm{mL}$ for CLP and $0.50 \mu \mathrm{g} / \mathrm{mL}$ and $1.5 \mu \mathrm{g} / \mathrm{mL}$ for $D X M$. No interference from matrices was observed and samples remained stable in the HPLC injector for $12 \mathrm{~h}$. The developed method was accurate that employed a simple liquid/liquid extraction procedure with recovery ranged $90.0 \%-101.9 \%$ for both analytes. Intra and inter-day precision were less than $2.5 \%$. The method was proved robust and reproducible that is applicable to pharmaceutical (active raw materials, syrups) and biological (blood) matrices.
\end{abstract}

Keywords: Dextromethorphan; Chlorpheniramine; Syrup; RPHPLC; DAD

\section{Introduction}

Dextromethorphan (DXM) is amongst the most commonly used over-the-counter anti-tussive ingredient of cough and cold medications. In cough syrups, it is available mostly in combination with sedating anti-histamine chlorpheniramine (CLP). DXM hydrobromide (Figure 1) is chemically (3-Methoxy-17-methylmorphinan hydro bromide monohydrate) [1-3]. It is an isomer of levorphanol and analog of codeine but lacks opiate-like analgesic activity and acts as cough suppressant at therapeutic doses. It is rapidly absorbed from the gastrointestinal tract and converted into lower active metabolite (dextrorphan). The duration of action after oral administration is approximately three to eight hours for DXM. CLP maleate (Figure 1) is chemically, (RS)-3-(4-chlorophenyl)3-(pyrid-2-yl) propyldimethylamine hydrogen maleate. It is an antihistamine drug that is widely used in pharmaceutical preparations for symptomatic relief of common cold and allergic diseases. It inhibits the effects of histamine on capillary permeability and bronchial smooth muscles. It is a first generation alkylamine antihistamine used in the prevention of the symptoms of allergic conditions such as rhinitis and urticaria.

In the United States Pharmacopeia 32/National Formulary 29, a method for analysis of pseudoephedrine (PEH) hydrochloride, DXM hydrobromide and CLP maleate using an ion-pairing reagent (sodium lauryl sulfate) was employed. The ion pairing remarkably reduces peak tailing and band broadening and involves usage of hydrophobic preservative like triethlyamine or alkyl sulfonate. These compounds are expensive and show strong affinity for stationary phase and less affinity for the mobile phase, which is ultimately not good for the health of the HPLC column. In addition, if we use an ion pairing agent in the mobile phase, it will increase the retention time $\left(t_{R}\right)$ of the target analytes, thus increase in analysis time [1]. Furthermore, the USP method is not simultaneous (i.e. for each analyte, different standard and sample preparations are needed). Many analytical methods are also described in the scientific literature for analysis of this combination. Gupta et al. had developed a HPLC method for the quantitation of paracetamol

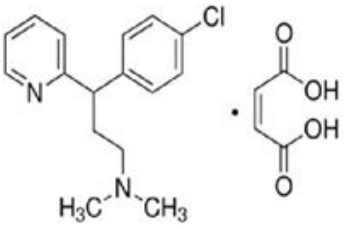

Chlorpheniramine maleate

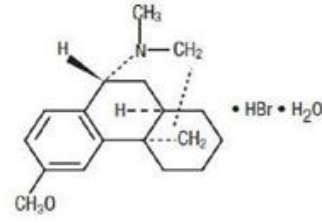

Dextromethorphan hydrobromid
(PCM), CLP maleate, DXM hydrobromide and phenylpropanolamine hydrochloride in different pharmaceutical dosage forms using a single column and three different mobile phases [2]. Biemer had described a simultaneous analysis of PCM, pseudoephedrine (PEH) hydrochloride and CLP maleate in tablet formulations using an isocratic mixed micellar mobile phase [3]. De Orsi et al. had developed a HPLC method for the determination of PCM, PEH hydrochloride, DXM hydrobromide and triprolidine in different pharmaceutical dosage forms using a reversed-phase (RP) C18 column and gradient elution and using two different wavelengths [4]. Patil et al. developed and validated an HPLC method for simultaneous determination of PCM, PEH hydrochloride, DXM hydrobromide and guaifenesin in bulk and pharmaceutical dosage forms using the technique of packed column

*Corresponding author: Humera Shafi, Punjab forensic science agency, Forensic Toxicology, Thokar niaz baig, Multan Road, Lahore, Punjab 53700, Pakistan, Email: humera.shafi@yahoo.com

Received July 01, 2018; Accepted July 17, 2018; Published July 24, 2018

Citation: Din NU, Shafi H, Imran M, Sarwar M, Tahir MA, et al. (2018) Validated Reversed-Phase Liquid Chromatographic Method for Simultaneous Determination of Dextromethorphan and Chlorpheniramine in Non-biological and Biological Matrices Using PDA Detector. Pharm Anal Acta 9: 590. doi: 10.4172/21532435.1000590

Copyright: $\odot 2018$ Shafi $\mathrm{H}$, et al. This is an open-access article distributed under the terms of the Creative Commons Attribution License, which permits unrestricted use, distribution, and reproduction in any medium, provided the original author and source are credited. 
Citation: Din NU, Shafi H, Imran M, Sarwar M, Tahir MA, et al. (2018) Validated Reversed-Phase Liquid Chromatographic Method for Simultaneous Determination of Dextromethorphan and Chlorpheniramine in Non-biological and Biological Matrices Using PDA Detector. Pharm Anal Acta 9: 590. doi: 10.4172/2153-2435.1000590

Page 2 of 6

supercritical fluid chromatography and a hypersil phenyl column with a ternary mobile phase [5]. Chen et al. had also described an HPLC method for simultaneous determination of CLP maleate, PCM and $\mathrm{PEH}$ hydrochloride in tablet formulations [6]. Milenkova et al. developed an HPLC method for simultaneous determination of PCM, PEH hydrochloride and DXM hydrobromide in tablet preparations [7] Murtha et al. described a method for simultaneous determination of PEH hydrochloride, DXM hydrobromide and CLP maleate in tablet preparations by second-derivative photodiode array spectroscopy [8]. Al-Rimawi developed a normal-phase liquid chromatographic method for simultaneous analysis of PEH hydrochloride, DXM hydrobromide, CLP maleate, and PCM in tablet formulations [9]. Silvana et al. validated a HPLC method for simultaneous determination of bromhexine, CLP, PCM and PEH in their combined cold medicine formulations [10]. Yu Ming et al. developed a non-ionic micellar liquid chromatographic method for simultaneous determination of PEH, PCM and CLP in cold compound preparations [11]. To the best of our knowledge, no method had been yet reported in literature for simultaneous estimation of DXM and CLP using RP-HPLC in active pharmaceutical ingredient raw materials, cough syrups and biological specimens like blood. Therefore, the present work was aimed to develop and validate a simple novel RPHPLC method, without using ion-pairing agent in the mobile phase, for simultaneous determination of DXM and CLP in various biological and non-biological matrices. The present RP-HPLC method was validated following the FDA and ICH guidelines

\section{Experimental Design}

\section{Chemicals and reagents}

The reference standards for dextromethorphan (DXM) hydrobromide and chlorpheniramine (CLP) maleate were purchased from Sigma Aldrich. HPLC grade methanol was obtained from Fischer chemicals. Ultrapure water (specific resistivity 18.2 M $\Omega$ ) was obtained from PCSIR laboratories complex Lahore. Analytical grade potassium dihydrogen phosphate, sodium hydroxide, chloroform and orthophosphoric acid were obtained from Merck, Germany. Over the counter cough syrups (Tyno syrup manufactured by Recko pharmaceuticals, Batch no. 5570 , stated potency on label: $5 \mathrm{~mL}$ of syrup contains DXM HBr $10 \mathrm{mg}$ and CLP maleate $2 \mathrm{mg}$ ) and active pharmaceutical ingredient (API) powdered raw materials were provided by the drug testing laboratory Lahore, Pakistan. All the excipients used for the development of placebo syrup formulation were obtained from drug testing laboratory Lahore, Pakistan and were used as such. Synthetic drug-free blood was obtained from Immunalysis Corporation, USA.

\section{HPLC instrumental conditions}

An Agilent 1200 series HPLC equipped with an auto-sampler and photodiode array detector was used. An isocratic elution was performed on Agilent C-18 HPLC column (15 cm length, $4.6 \mathrm{~mm}$ internal diameter; $5 \mu \mathrm{m}$ particle size). $10 \mu \mathrm{L}$ injection volume, $25^{\circ} \mathrm{C}$ $\pm 2^{\circ} \mathrm{C}$ column temperature, $230 \mathrm{~nm}$ detection wave-length, $0.8 \mathrm{~mL} /$ min flow rate and 8 minutes run time were employed for analysis. Integration of the chromatography response was carried out using Chemstation software. Quantification was achieved by the peak-area ratio method with reference to the external standard.

\section{Preparation of mobile phase}

$0.1 \mathrm{M}$ Potassium dihydrogen phosphate buffer was prepared by dissolving $13.6 \mathrm{~g}$ of potassium dihydrogen phosphate in $900 \mathrm{ml}$ ultrapure water in a $1000 \mathrm{~mL}$ clean and dry flask. The mixture was stirred well for complete dissolution of the salt. Further $100 \mathrm{~mL}$ of water was added and the $\mathrm{pH}$ was adjusted to 3.0 using ortho phosphoric acid. The mixture of HPLC grade methanol and phosphate buffer $(60: 40, \mathrm{v} / \mathrm{v})$ was degassed and filtered through $0.45 \mu \mathrm{m}$ Millipore membrane filter.

\section{Diluent preparation}

The diluent was prepared by mixing HPLC grade methanol and phosphate buffer solution ( $\mathrm{pH} 3.0)$ in the ratio of 50: $50(\mathrm{v} / \mathrm{v})$. This solution was used for diluting the standard drug and sample solutions in the study.

\section{Preparation of standard solution}

Stock standard solution was prepared by dissolving $100 \mathrm{mg}$ of DXM hydrobromide and $20 \mathrm{mg}$ of CLP maleate in $100 \mathrm{~mL}$ of diluent. Solution was ultra-sonicated for $15 \mathrm{~min}$ to ensure complete dissolution. This stock standard solution contains $1000 \mu \mathrm{g} / \mathrm{mL}$ of DXM hydrobromide and $200 \mu \mathrm{g} / \mathrm{mL}$ of CLP maleate. Two such stock standard solutions were prepared using two separate weighing. One stock solution was used in preparation of working standard dilutions at concentrations ranging from $0.15-200 \mu \mathrm{g} / \mathrm{mL}$ for CLP and $0.25-1000 \mu \mathrm{g} / \mathrm{mL}$ for DXM to be used in linearity, LOD and LOQ studies. Second stock solution was used to prepare positive quality control (QC) samples in drug-free (placebo) formulation and synthetic blood for recovery procedure.

\section{Sample preparation}

API raw material sample: Sample solution of API raw material was prepared by dissolving $10 \mathrm{mg}$ of powder API in $100 \mathrm{~mL}$ of diluent. $1 \mathrm{~mL}$ of this sample solution was then transferred to a $2 \mathrm{~mL}$ HPLC glass vial for analysis.

Pharmaceutical syrup and biological sample: $1 \mathrm{~mL}$ of each sample was taken in separately labeled $15 \mathrm{~mL}$ centrifuge tubes. $0.1 \mathrm{~N}$ sodium hydroxide solution was added to all samples to achieve the $\mathrm{pH}$ near to 9.5 and vortexed thoroughly. $2 \mathrm{~mL}$ of chloroform was added to each tube, tubes were capped, rotated for 15 minutes on circular rotator, centrifuged for 10 minutes and organic layer was then separated. Each sample was extracted twice with $2 \mathrm{~mL}$ of chloroform in the same way. The two organic extracts were then combined and completely evaporated to dryness. The residue was reconstituted in $1 \mathrm{~mL}$ of diluent and transferred to a $2 \mathrm{~mL}$ HPLC glass vial for analysis.

\section{Results and Discussion}

\section{Method development and optimization}

Preliminary studies involved testing several mobile phase compositions, flow rates, injection volumes and detection wavelengths for the effective separation of DXM and CLP. Silica column $(15 \mathrm{~cm} \mathrm{x}$ $4.6 \mathrm{~mm} \times 5 \mu \mathrm{m}$ ) eluted with a mobile phase of methanol/potassium dihydrogen phosphate buffer $(60: 40, \mathrm{v} / \mathrm{v})$ at a flow rate of $0.8 \mathrm{~mL} / \mathrm{min}$ and a detection wavelength of $230 \mathrm{~nm}$ afforded the best separation of these analytes (Figure 2 and Table 1).

\section{Method validation}

After method development, the validation of the current method has been performed in accordance with FDA and ICH guidelines which included accuracy, precision, selectivity, linearity, range, stability, robustness and ruggedness [12-16].

Assay linearity and calibration range: To evaluate linearity of the method, different concentrations of two analytes in the range of 1-1000 $\mu \mathrm{g} / \mathrm{mL}$ for DXM hydrobromide and $0.5-200 \mu \mathrm{g} / \mathrm{mL}$ for CLP maleate were analyzed. Six-points standard curves for both compounds were 


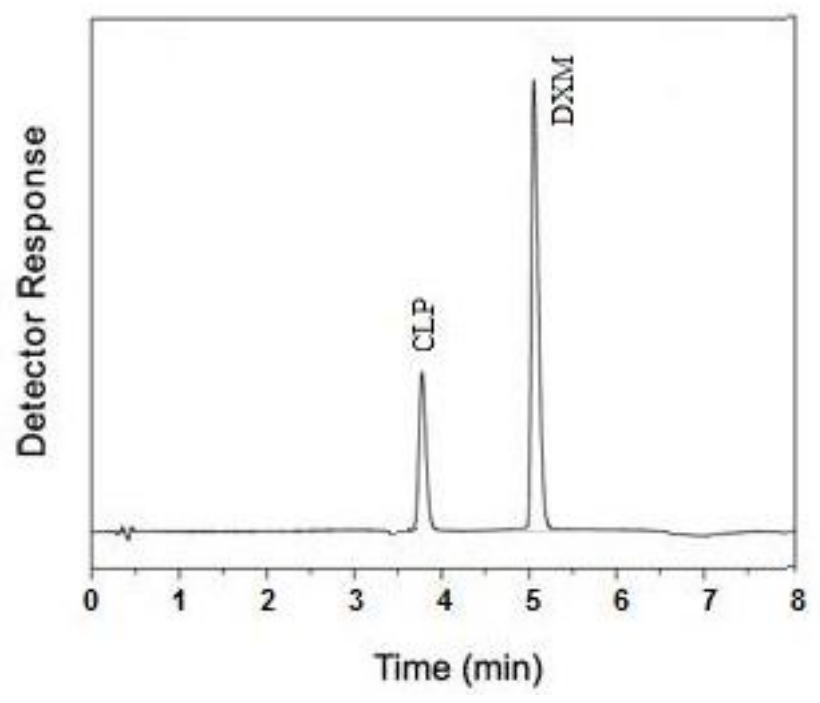

Figure 2: Chromatogram of DXM and CLP in standard stock solution.

constructed by drawing peak area versus DXM and CLP processed separately and run in triplicate daily for 3 consecutive days (Figure 3). The current method demonstrated good linearity over the range of $1-200 \mu \mathrm{g} / \mathrm{mL}$ for CLP with $\mathrm{R}^{2}$ of 0.9994 and $2-1000 \mu \mathrm{g} / \mathrm{mL}$ for DXM with $\mathrm{R}^{2}$ of 0.9993 . The relative standard deviations (RSDs) of the slopes were $\leq 2.1 \%$ for both analytes $(\mathrm{n}=54)$.

Limit of detection (LOD) and limit of quantification (LOQ): The LOD (sensitivity) and LOQ for both analytes were determined, based on signal-to-noise concept, as the lowest concentrations at which signalto-noise ratio is between 3 or 2: 1 and 10: 1 respectively with defined precision and accuracy under the given experimental conditions. In the present study, the limits of detection (LOD) and quantification (LOQ) were $0.25 \mu \mathrm{g} / \mathrm{mL}$ and $1.0 \mu \mathrm{g} / \mathrm{mL}$ for CLP and $0.50 \mu \mathrm{g} / \mathrm{mL}$ and $1.5 \mu \mathrm{g} /$ $\mathrm{mL}$ for DXM respectively.

Assay accuracy (recovery) and precision: Accuracy of the method was performed by recovery study of drug-spiked placebo formulations and blank blood at five concentrations (one near to the limits of quantitation). Each concentration was run in triplicate on a single assay day to determine intra-day precision and accuracy. In addition, these five positive quality control (QC) samples were analyzed for 3 consecutive days to determine inter-day precision and accuracy. The mean observed concentrations for all QC samples were calculated based on calibration curves. The repeatability (intra-assay precision) and the intermediate (between-assay or inter-assay) precision were calculated from data obtained during three days validation. The recovery of these two active ingredients from the spiked samples (including LOQ sample) was at the range of $90.0 \%-101.9 \%$ and lies within the recommended tolerance of $80 \%-115 \%$. The intra-day precisions of three replicates on the same day for four concentrations were $\leq 1.3 \%$ and for LOQ concentrations were $\leq 2.5 \%$. The inter-day precisions for five replicates in three consecutive days were $\leq 1.6 \%$ for both analytes at five concentrations including LOQ. From Tables 2 and 3, it appears that both precision and accuracy were within acceptable limits for routine drug analysis (15\%). As repeatability, precision data for six replicates at concentrations of 50 $\mu \mathrm{g} / \mathrm{mL}$ and $200 \mu \mathrm{g} / \mathrm{mL}$ of DXM were $\leq 1.5 \%$ and at $10 \mu \mathrm{g} / \mathrm{mL}$ and 40 $\mu \mathrm{g} / \mathrm{mL}$ of CLP were $\leq 2.0 \%$, which lie within recommended tolerance of $\leq 2.0 \%$. The measuring precisions were determined $\leq 0.7 \%$ and $\leq$ $0.2 \%$ for DXM and CLP, respectively, after six injections as an indicator of instrument precision lies within recommended tolerance of $\leq 1.0 \%$. Shah et al. recommended that an analytical method may be considered validated in terms of accuracy if the mean value is within $\pm 15 \%$ of the actual value. Similarly, it is also suggested that the analytical method may be considered validated in terms of precision if the precision around the mean value does not exceed a $15 \%$ coefficient of variation (CV or RSD) [17].

Specificity and selectivity: Selectivity of the current method was demonstrated by good separation of two analytes from each other at retention times 3.38 and $5.02 \mathrm{~min}$ for CLP and DXM respectively (Figure 2). Furthermore, drug-free placebo syrup formulation and synthetic blood specimen were analyzed as negative quality control samples along with spiked (drug-added) placebo formulation and blood specimen to determine the specificity of proposed method. No interfering peaks were encountered in the blank samples. Injection of blank phosphate buffer into HPLC column represented that no peak could be seen on chromatogram. Results showed no excipient and/or matrix interference in quantification of DXM and CLP at the reported wavelength. The total chromatography run time was prolonged by 8 min to allow for a late eluting peak. The chromatographic run time of $8 \mathrm{~min}$ was sufficient for sample analysis that allows analyzing large number of samples in a short period of time.

Robustness: Robustness of an analytical method is a measure of its capacity to remain unaffected by small but deliberate variations in method parameters and provides an indication of its reliability during normal usage. Robustness of the current method was investigated by slight modifications in optimized HPLC conditions. Small variations were made in the following chromatographic parameters: (a) flow rate: $0.7 \mathrm{~mL} / \mathrm{min}$ and $0.9 \mathrm{~mL} / \mathrm{min}$ instead of $0.8 \mathrm{~mL} / \mathrm{min}$, (b) detection wavelength: $225 \mathrm{~nm}$ and $235 \mathrm{~nm}$ instead of $230 \mathrm{~nm}$, and (c) volume fraction of methanol: $55 \%$ and $65 \%$ instead of $60 \%$. From the results, it was indicated that the selected factors remained unaffected by small variations in these quantities as well as the method was robust even by change in flow rate $\pm 0.1 \mathrm{~mL} / \mathrm{min}$, change in methanol volume $\pm 5 \%$ and change in detection wavelength $\pm 5 \mathrm{~nm}$.

Ruggedness: Ruggedness of the current method was demonstrated by analyzing six samples (assay) of syrup and blood by two analysts in the same laboratory. The RSD calculated for the 12 samples were $0.62 \%$ and $0.49 \%$ for DXM and CLP, respectively, indicating the ruggedness of the method.

Stability: In the case of an unexpected delay during analysis, it is important to have information about the stability of all solutions. In this study, the stability of DXM and CLP in the working standard solution and sample preparations were studied. The responses for the aged solutions were evaluated using a freshly prepared standard. DXM and CLP did not show evidence of significant degradation for at least $12 \mathrm{~h}$, when kept in auto-sampler $\left(22^{\circ} \mathrm{C}\right)$. During this period, results do not decrease below $95 \%$. The lack of instability allowed a large batch of samples to be processed in one assay run.

\section{Analysis of API powders, pharmaceutical dosage form (syrup) and biological specimens (blood)}

Identification by GC-MS: Samples of API raw materials, syrup samples and blood specimens were extracted with chloroform; separated organic layer was then evaporated to dryness and reconstituted with 100 $\mu \mathrm{L}$ of methanol. Qualitative analysis of these samples was performed on an Agilent 7890A GC coupled to a 5975C inert mass selective detector (MSD) with an inert source operating in electron impact mode. The 
Citation: Din NU, Shafi H, Imran M, Sarwar M, Tahir MA, et al. (2018) Validated Reversed-Phase Liquid Chromatographic Method for Simultaneous Determination of Dextromethorphan and Chlorpheniramine in Non-biological and Biological Matrices Using PDA Detector. Pharm Anal Acta 9: 590. doi: 10.4172/2153-2435.1000590

Page 4 of 6

\begin{tabular}{|c|c|c|c|c|c|c|}
\hline Analyte & $\begin{array}{c}\text { Retention time }\left(t_{R}\right) \\
(\min .)\end{array}$ & $\begin{array}{l}\text { Capacity factor } \\
\text { (k) }\end{array}$ & Resolution & Theoretical plates & Asymmetry & $\begin{array}{l}\text { Selectivity } \\
\text { (a) }\end{array}$ \\
\hline DXM hydrobromide & $5.02 \pm 0.10$ & 5.2 & 2.1 & 2500 & 1.2 & 1.5 \\
\hline CLP maleate & $3.83 \pm 0.10$ & 7.1 & 1 & 2200 & 1.1 & 1.3 \\
\hline
\end{tabular}

Table 1: Chromatographic parameters of the separated analytes in Figure 2.

\begin{tabular}{|c|c|c|c|c|}
\hline Spiked QC conc. ( $\mu \mathrm{g} / \mathrm{mL})$ & Conc. (mean \pm SD) $(\mu \mathrm{g} / \mathrm{mL})$ & found & Precision (\%RSD) & Accuracy (\%) \\
\hline \multicolumn{5}{|c|}{ DXM hydrobromide } \\
\hline 1.5 & \multicolumn{2}{|c|}{$1.40 \pm 0.04$} & 2.5 & 93.3 \\
\hline 10 & \multicolumn{2}{|c|}{$10.13 \pm 0.13$} & 1.3 & 101.3 \\
\hline 100 & \multicolumn{2}{|c|}{$100.96 \pm 0.80$} & 0.8 & 101 \\
\hline 500 & \multicolumn{2}{|c|}{$504.27 \pm 1.69$} & 0.4 & 100.9 \\
\hline 1000 & \multicolumn{2}{|c|}{$976.64 \pm 1.15$} & 0.1 & 97.6 \\
\hline \multicolumn{5}{|c|}{ CLP maleate } \\
\hline 1 & \multicolumn{2}{|c|}{$0.97 \pm 0.02$} & 1.7 & 97 \\
\hline 2 & \multicolumn{2}{|c|}{$2.23 \pm 0.05$} & 0.5 & 111.5 \\
\hline 20 & \multicolumn{2}{|c|}{$21.63 \pm 0.17$} & 0.8 & 108.2 \\
\hline 100 & \multicolumn{2}{|c|}{$99.86 \pm 1.12$} & 1.2 & 99.9 \\
\hline 200 & \multicolumn{2}{|c|}{$197.67 \pm 0.99$} & 0.5 & 98.8 \\
\hline
\end{tabular}

Table 2: Intra-assay variability of DXM and CLP obtained from five levels of QC samples.

\begin{tabular}{|c|c|c|c|}
\hline Spiked QC conc. $(\mu \mathrm{g} / \mathrm{mL})$ & Conc. (mean $\pm \mathrm{SD})(\mu \mathrm{g} / \mathrm{mL})$ & Precision (\%RSD) & Accuracy (\%) \\
\hline \multicolumn{4}{|c|}{ DXM hydrobromide } \\
\hline 1.5 & $1.49 \pm 0.01$ & 0.6 & 99.3 \\
\hline 10 & $10.02 \pm 0.09$ & 0.9 & 100.2 \\
\hline 100 & $100.33 \pm 1.09$ & 1.1 & 100.3 \\
\hline 500 & $502.28 \pm 0.08$ & 0 & 100.5 \\
\hline 1000 & $999.89 \pm 1.00$ & 0.1 & 99.98 \\
\hline \multicolumn{4}{|c|}{ CLP maleate } \\
\hline 1 & $0.95 \pm 0.01$ & 0.6 & 95 \\
\hline 2 & $2.12 \pm 0.03$ & 1.6 & 106 \\
\hline 20 & $21.43 \pm 0.13$ & 0.6 & 107.2 \\
\hline 100 & $99.67 \pm 1.09$ & 1.1 & 99.7 \\
\hline 200 & $197.47 \pm 0.91$ & 0.5 & 98.7 \\
\hline
\end{tabular}

Table 3: Inter-assay variability of DXM and CLP obtained from five levels of QC samples.

GC column used was DB-5MS (30 m x $250 \mu \mathrm{m} \times 0.25 \mu \mathrm{m}$, J and W Scientific). Ten microliter $(10 \mu \mathrm{L})$ syringe, splitless injection mode and $1 \mu \mathrm{L}$ injection volume were selected for the full scan spectrum. The initial oven temperature was $80^{\circ} \mathrm{C}$, holds for $1 \mathrm{~min}$, and then ramped at $10^{\circ} \mathrm{C} / \mathrm{min}$ to $280^{\circ} \mathrm{C}$, and hold for $9 \mathrm{~min}$. Scanning mass range was 43 550 a.m.u. AAFS (American Academy of Forensic Sciences) and NIST (National institute of Science and Technology) mass spectral libraries were used for identification of drug analytes in the tested samples. Qualitative analysis revealed the presence of DXM and CLP in the API raw materials, syrups and blood specimens. No unusual ingredients were detected. However, as the GC column and method used was unable to discriminate DXM from its levo-isomer (levomethorphan), no indication regarding its presence was made based on this method. Figure 4 showed the GC chromatograph (A) and Mass spectrum (B) of syrup sample containing DXM and CLP.

Quantitative analysis by proposed and validated RP-HPLC method: DXM and CLP were quantified in the API powders, syrups and blood specimens using the proposed method (Figure 5). The Tyno syrup samples of same batches were also sent to external independent drug testing laboratory, Medicines and Healthcare Products Regularity Agency (MHRA) UK, for further analysis by the Government of Pakistan. All the tests performed and observations recorded revealed that both API samples and syrups were sub-standard. MHRA results also showed that the syrups and API samples were contaminated with varying amounts of levomethorphan, a narcotic opioid. The concentrations of DXM determined were not equivalent to that labeled on the cough syrups. More than 50 deaths were reported in Pakistan after consuming this contaminated cough syrup [18]. Postmortem samples of 19 males ages ranged 17-45 years, who abused this syrup for recreational purposes, were received to the forensic toxicology department of Punjab Forensic Science Agency for analysis. Postmortem peripheral blood specimens of deceased were analyzed using this method along with samples of API powders and tyno cough syrups. The results are summarized in Table 4.

\section{Conclusion}

A RP-HPLC method for simultaneous determination of DXM and CLP at a single wavelength in biological as well as non-biological specimens has not yet been reported. The presented method in addition to its novelty for determination of two analytes at single wavelength in various matrices is sufficiently rapid, simple and sensitive as well as precise and accurate that complies with FDA and ICH guidelines for accuracy, precision, reproducibility and stability for standards and QC samples. The assay of the two analytes was not interfered by the excipients and other matrix effects. The linearity, accuracy, precision, limit of detection and quantification, specificity-selectivity 
Citation: Din NU, Shafi H, Imran M, Sarwar M, Tahir MA, et al. (2018) Validated Reversed-Phase Liquid Chromatographic Method for Simultaneous Determination of Dextromethorphan and Chlorpheniramine in Non-biological and Biological Matrices Using PDA Detector. Pharm Anal Acta 9: 590. doi: 10.4172/2153-2435.1000590

Page 5 of 6
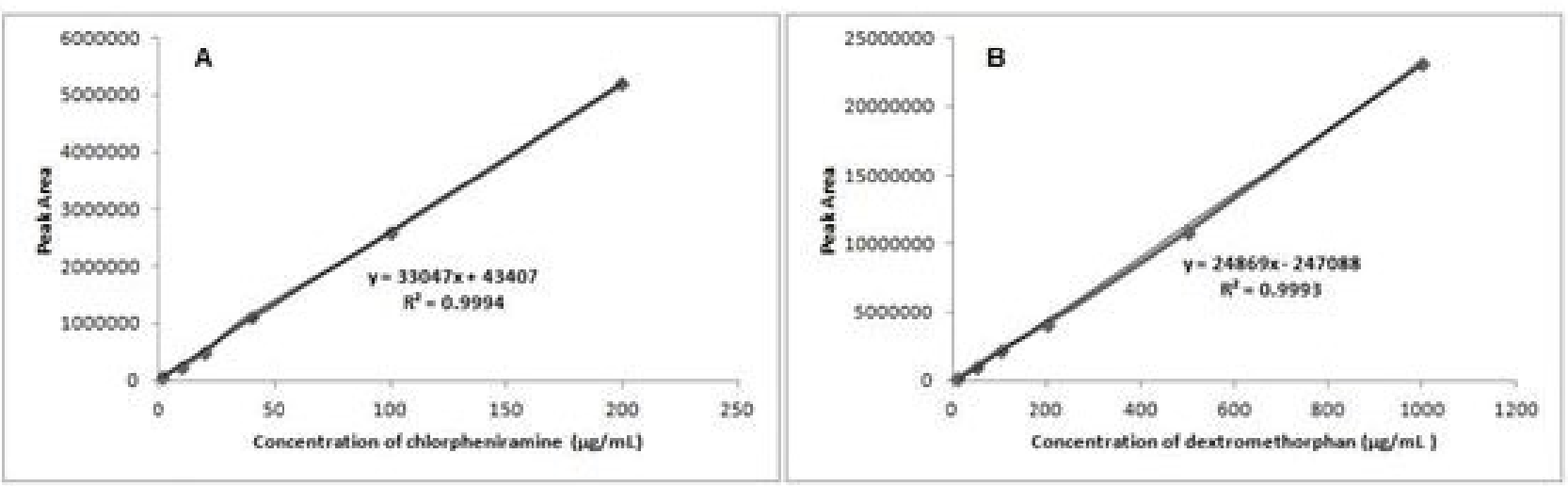

Figure 3: Linearity graphs for CLP maleate (A) and DXM hydrobromide (B).

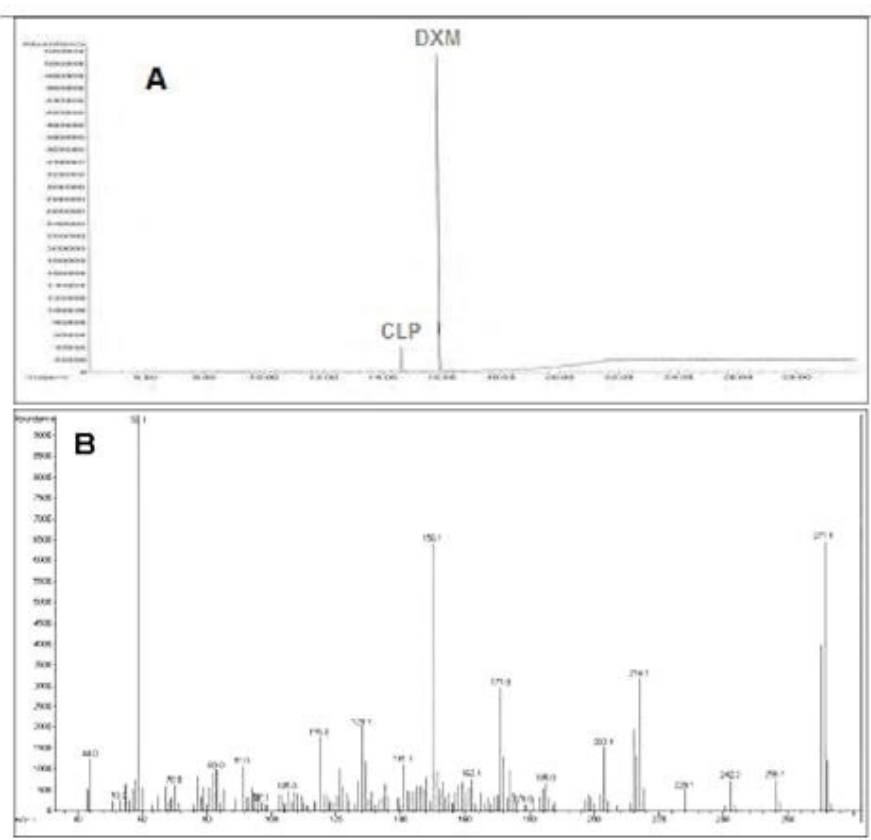

Figure 4: Representative chromatogram (A) and mass spectrum (B) of cough syrup sample containing DXM and CLP.
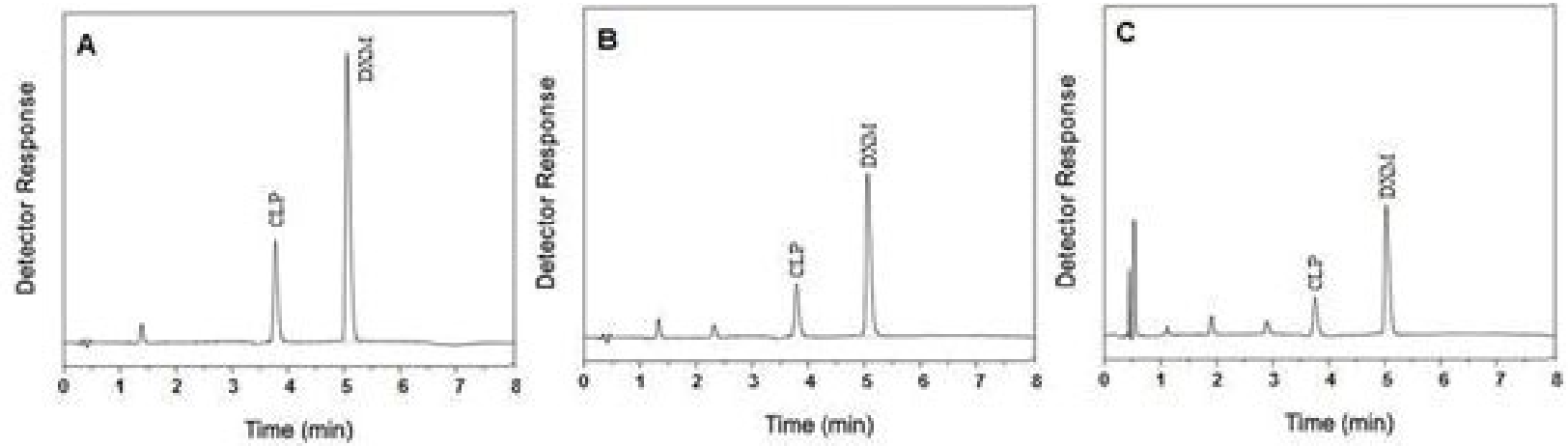

Figure 5: Representative chromatograms of API sample (A), cough syrup sample (B) and blood sample (C) containing DXM and CLP. 
Citation: Din NU, Shafi H, Imran M, Sarwar M, Tahir MA, et al. (2018) Validated Reversed-Phase Liquid Chromatographic Method for Simultaneous Determination of Dextromethorphan and Chlorpheniramine in Non-biological and Biological Matrices Using PDA Detector. Pharm Anal Acta 9: 590. doi: 10.4172/2153-2435.1000590

Page 6 of 6

\begin{tabular}{|c|c|c|}
\hline Sample & Conc. Of DXM (D+L) & Conc. Of CLP \\
\hline Syrup bottle-1 & $9.61 \mathrm{mg} / 5 \mathrm{~mL}$ & $1.88 \mathrm{mg} / 5 \mathrm{~mL}$ \\
\hline Syrup bottle-2 & $9.73 \mathrm{mg} / 5 \mathrm{~mL}$ & $1.79 \mathrm{mg} / 5 \mathrm{~mL}$ \\
\hline Syrup bottle-3 & $8.11 \mathrm{mg} / 5 \mathrm{~mL}$ & $1.56 \mathrm{mg} / 5 \mathrm{~mL}$ \\
\hline Syrup bottle-4 & $9.75 \mathrm{mg} / 5 \mathrm{~mL}$ & $1.92 \mathrm{mg} / 5 \mathrm{~mL}$ \\
\hline API Powder-1 & $99.10 \%$ & Not detected \\
\hline API Powder-2 & $97.90 \%$ & Not detected \\
\hline Postmortem blood & Amounts obtained range & $\begin{array}{c}\text { Amounts obtained } \\
\text { range from }\end{array}$ \\
\hline Specimens (n=19) & from 7.3 to $41.7 \mathrm{mg} / \mathrm{L}$ & \begin{tabular}{c}
0.9 to $2.5 \mathrm{mg} / \mathrm{L}$ \\
\hline 'Postmortem blood specimens of 19 deceased males received to author's \\
laboratory for toxicological analysis.
\end{tabular} \\
\hline
\end{tabular}

Table 4: Concentration of DXM and CLP in test samples.

of the method and sample stability were established. This rapid and reproducible analytical method was successfully used for analysis of pharmaceutical raw materials, syrup samples and postmortem blood specimens.

\section{Funding/Acknowledgement}

None to declare

\section{Conflict of Interest}

\section{None}

\section{References}

1. Milenkova K, Dimitrovska A, Ugrinova L, Trajković-Jolevska S (2003) Simultaneous determination of paracetamol, pseudoephedrine hydrochloride and dextromethorphan hydrobromide in tablets by HPLC. Bull Chem Tech 22: 33-37.

2. Gupta VD, Heble AR (1984) Quantitation of acetaminophen, chlorpheniramine maleate, dextromethorphan hydrobromide, and phenylpropanolamine hydrochloride in combination using high-performance liquid chromatography. J Pharm Sci 73: 1553-1556.

3. Biemer TA (1987) Simultaneous analysis of acetaminophen, pseudoephedrine hydrochloride and chlorpheniramine maleate in a cold tablet using an isocratic, mixed micellar high-performance liquid chromatographic mobile phase. J Chromatography A 410: 206-210.

4. De Orsi D, Gagliardi L, Bolasco A, Tonelli D (1996) Simultaneous determination of triprolidine, pseudophedrine, paracetamol and dextromethorphan by HPLC. Chromatographia 43: 496-500.

5. Patil KM, Bhoir IC, Raman B, Sundaresan M (2001) Concurrent Assay O Acetaminophen, Pseudoephedrine, Guaifenesin And Dextromethrophan In
Formulations By Packed Column Supercritical Fluid Chromatography. Ind J Pharm Sci 63: 468-472.

6. Chen ZL, Zhang L, Wang M, Huang Y (2001) Simultaneous determination of chlorpheniramine, paracetamol and pseudo-ephedrine hydrochloride in composite tablets by high performance liquid chromatography. Chi J Chrom 19: $236-238$

7. Milenkova K, Dimitrovska A, Ugrinova L, Trajkovic-Jolevska S (2003) Simultaneous determination of paracetamol, pseudoephedrine hydrochloride and dextromethorphan hydrobromide in tablets by HPLC. Bullet Chem Technol 22: 33-37.

8. Murtha JL, Julian TN, Radebaugh GW (1988) Simultaneous determination of pseudoephedrine hydrochloride, chlorpheniramine maleate, and dextromethorphan hydrobromide by second-derivative photodiode array spectroscopy. J Pharm Sci 77: 715-718.

9. Al-Rimawi F (2010) Normal-phase LC method for simultaneous analysis of pseudophedrine hydrochloride, dextromethorphan hydrobromide chlorpheniramine maleate, and paracetamol in tablet formulations. Saudi Pharm J 18: 103-106.

10. Vignaduzzo SE, Kaufman TS (2013) Development and validation of a HPLC method for the simultaneous determination of bromhexine, chlorpheniramine, paracetamol, and pseudoephedrine in their combined cold medicine formulations. J Liq Chrom Rel Technol 36: 2829-2843.

11. Dong YM, Li N, An Q, Lu NW (2015) A Novel nonionic micellar liquid chromatographic method for simultaneous determination of pseudoephedrine, paracetamol, and chlorpheniramine in cold compound preparations. J Liq Chrom Rel Technol 38: 251-258.

12. FDA (2000) Guidelines for industry: analytical procedures and method validation (Draft guidance). Food and Drug Administration, Rockville, USA

13. FDA (1994) Reviewer guidance: validation of chromatographic methods. Food and Drug Administration, Rockville, USA.

14. FDA (2001) Guidelines for Industry: Bioanalytical method validation. Food and Drug Administration, Rockville, USA.

15. ICH (1994) Text on validation of analytical procedures. International Conference on Harmonisation, IFPMA, Geneva.

16. ICH (1996) Validation of analytical procedures: methodology. International Conference on Harmonisation, IFPMA, Geneva.

17. Shah VP, Midha KK, Dighe S, McGilveray IJ, Skelly JP, et al. (1992) Analytical methods validation: Bioavailability, bioequivalence, and pharmacokinetic studies. Int J Pharm 82: 1-7.

18. Shafi H, Imran M, Usman HF, Sarwar M, Tahir MA, et al. (2016) Deaths due to abuse of dextromethorphan sold over-the-counter in Pakistan. Egyptian $J$ Forensic Sci 6: 280-283. 